Research paper

\title{
Analysis of skim milk powder deposition on stainless steel tubes in cross-flow
}

\author{
T.G. Walmsley*, M.R.W. Walmsley, M.J. Atkins, J.R. Neale \\ Energy Research Centre, School of Engineering, University of Waikato, Hamilton 3216, New Zealand
}

\section{H I G H L I G H T S}

- Skim milk powder deposition on round, elliptical and turned squared tubes is tested.

- Powder deposited almost exclusively on the various tubes' front faces.

- Elliptical tube is shown to be naturally low fouling due to its shape.

- The critical impact angle is a function of particle stickiness and air velocity.

\section{A R T I C L E I N F O}

\section{Article history:}

Received 7 June 2014

Accepted 7 October 2014

Available online xxx

\section{Keywords:}

Heat exchanger

Particulate fouling

Heat recovery

Powder deposition

\begin{abstract}
A B S T R A C T
Particulate fouling on the gas side of heat recovery equipment is a common industrial problem. The aim of this study is to characterize the deposition of skim milk powder on a single bare tube in cross-flow. A custom built rig is applied to simulate exhaust air conditions that is experienced in an exhaust exchanger. For a constant airflow rate, increasing particle stickiness resulted in greater deposition coverage around the front of the round and elliptical tubes peaking in the middle, whereas the turned square tube tended to be either clear or covered. Results show that the skim milk powder particle impact angle on the tube, as opposed to the wall shear stress, is an important determinant for deposition. During each test and at the conclusion of each test, which was when fouling reached an asymptote, the amount of deposition coverage and build-up on the tube varied depending on the tube shape, particle stickiness, and air velocity.
\end{abstract}

๑) 2014 Elsevier Ltd. All rights reserved.

\section{Introduction}

Heat exchanger fouling is costly and affects a wide range of industries [1]. Severe heat exchanger fouling levels significantly degrades thermal and hydraulic performance. Common design techniques to mitigate fouling [2] include (i) increasing velocity, (ii) implanting inserts between or within tubes, (iii) non-standard tube geometries (e.g. elliptical tubes), (iv) non-standard fin geometries, and (v) low surface energy coatings.

Abd-Elhady et al. [3] developed the concept of a dimensionless rolling moment, which is defined as the hydrodynamic rolling moment divided by the adhesion resting moment, to calculate a limiting fouling velocity that theoretically predicts the onset of fouling, and shows close agreement with lab-scale experimental results [4]. The literature contains a variety of methods that reduce fouling by increasing the air turbulence and wall shear stress, such

\footnotetext{
* Corresponding author.

E-mail address: timgw@waikato.ac.nz (T.G. Walmsley).
}

as placing inserts between tubes [5], adding a non-heat transferring "spoiler" tube row at the front of a compact heat exchanger [6], and using non-standard shaped tubes Paz et al. [7] focused on fouling in diesel exhaust gases and showed the close relationship between wall shear stress and deposition. Using this link between wall shear stress and fouling, Walmsley et al. [8] developed CFD (Computational Fluid Dynamics) models to examine a wide range of tubes for their fouling, heat transfer and pressure drop characteristics.

Heat recovery from milk spray dryer exhaust airflows has the potential to increase the process's heat efficiency by 10-20\% [9], but its uptake New Zealand industry has been subdued due to concerns over fouling, effectively causing worst-case economics to be very poor. In the mid-1980's the New Zealand Plains Co-Op Dairy Ltd factory installed a glass tube air-to-air exhaust heat recovery system. Energy surveys of its performance showed heat recovery decreased by $40 \%$ after $13 \mathrm{~h}$ of operation. In the late 2000's, a new $20+\mathrm{t} / \mathrm{h}$ state-of-the-art spray dryer was built in NZ costing over US\$200 million, which plan to include spray dryer exhaust heat recovery using a liquid coupled loop. The exhaust heat exchanger was built but never installed due to concerns over milk powder 


\begin{tabular}{|c|c|c|c|}
\hline \multicolumn{2}{|c|}{ Nomenclature } & $\alpha$ & time constant, s \\
\hline \multicolumn{2}{|c|}{ Variables } & \multicolumn{2}{|c|}{ Subscript } \\
\hline$a_{w}$ & water activity, dimensionless & 1 & state 1 \\
\hline$c$ & powder concentration, $\mathrm{mg} / \mathrm{m}^{3}$ & 2 & state 2 \\
\hline$\Delta P$ & percent change in differential pressure, \% & $a$ & adhesion \\
\hline$k$ & material constant in Eq. (2), dimensionless & $b$ & bulk \\
\hline$m$ & mass fraction, dimensionless & $f$ & fouling \\
\hline RM & rolling moment, dimensionless & $l$ & lactose \\
\hline$t$ & time, $s$ & $p$ & particle \\
\hline$T$ & air temperature, ${ }^{\circ} \mathrm{C}$ & $S$ & solid \\
\hline$T_{g}$ & glass transition temperature, ${ }^{\circ} \mathrm{C}$ & $w$ & water \\
\hline$X$ & mass fraction of water on a dry basis, dimensionless & & \\
\hline
\end{tabular}

fouling causing disruptions to plant production. Since that time an additional twelve milk powder spray dryers have been built in New Zealand all without exhaust heat recovery.

The aim of this study is to experimentally characterize the deposition of SMP (Skim Milk Powder) on a single bare tube in cross-flow. Tube geometries examined include round, elliptical and turned square tubes. For each test the air temperature and absolute humidity is selected to mimic various locations within an exhaust heat recovery system. Experimental deposition tests are performed using the same rig as reported Walmsley et al. [10]. The experimental results are analysed in terms of localised wall shear stresses [7] and particle impact angle [11] to determine which is important in relation to the deposition of milk powder. Results are compared to the experimentally validated SMP deposition model reported by Walmsley et al. [12] for deposition in an in impingement jet on an angled flat plate. The overall goal is to provide empirical evidence that quantifies the effect of fouling on the thermal and hydraulic performance of milk dryer exhaust recuperators and find effective ways to minimise fouling through good heat exchanger selection and design.

\section{Theory}

\subsection{Particle transport and deposition processes}

Deposition of particles may result from a combination of several discrete transport processes and mechanisms [13]. These processes are largely dependent on the dimensionless particle relaxation time $\left(t^{+}\right)$, which is a function of the particle's density and radius and the fluid's density, viscosity, and wall shear stress. The particle relaxation time represents the time scale with which the particles respond to changes in the slip velocity. Typically, three general transport regimes are identified: (1) turbulent diffusion $\left(t^{+}<0.1\right)$, (2) turbulent diffusion-eddy impaction $\left(0.1<t^{+}<10\right)$ and (3) particle inertia moderated $\left(t^{+}>10\right)$. In the turbulent diffusion regime, deposition is a mass transport problem described by Fick's law. The second regime is a transitional regime whereas particles that fall in the particle inertia regime respond slowly to changes in velocity flow field changes as indicated by the large $t^{+}$.

Beyond these fundamental mechanisms of deposition, researchers have attempted to establish important local and global parameters that can be calculated and optimised to minimise fouling.

\subsubsection{Critical wall shear stress}

Paz et al. [7] attempted to show how the localised wall shear stress provides a better description and tool for predicting when "rolling" occurs. They define the critical wall shear stress as the minimum shear stress value to cause RM to equal unity. Because the local wall shear stress of a tube in cross-flow varies around the profile of the tube, it is expected that any area with a wall shear stress above the critical value will experience no deposition.

\subsubsection{Critical impact angle}

The critical impact angle (refer to Fig. 8) is the angle beyond which no particles will stick to a surface resulting in minimal fouling [14]. This concept is based on an energy balance between a particle's tangential kinetic energy of impact and the minimum energy required to break its adhesive contact with the surface. Since the adhesion energy is related to particle stickiness, it is anticipated that the critical impact angle changes depending on the air velocity and conditions, which determine the particle stickiness.

\subsection{Understanding milk powder stickiness}

Many studies have shown that the stickiness behaviour of amorphous powders can be described by the extent to which the air temperature, $T$, exceeds the glass transition temperature, $T_{g}$, of the major amorphous components of the material, i.e. $T-T_{g}$ [15]. For SMP the main amorphous component is lactose, which is about $52 \mathrm{wt} \%$ of SMP.

The glass transition temperature of lactose is usually determined using thermal methods such as DSC (Differential Scanning Calorimetry). Performing DSC on every sample of milk powder at each condition tested would be time consuming and highly impractical. However Brooks [16] developed a third order empirical polynomial model for predicting the $T_{g}$ of lactose at a given particle surface water activity $\left(a_{w}\right)$, which is assumed to be in equilibrium with the air relative humidity. This model is shown in Eq. (1) and is accurate for $a_{w}$ in the range of $0-0.575$.

$T_{g}=-530.66\left(a_{w}\right)^{3}+652.06\left(a_{w}\right)^{2}-366.33\left(a_{w}\right)+99.458$

For situations where the relative humidity is above $57.5 \%$ the Gordon and Taylor equation (Eq. (2)) can be used to predict $T_{g}$. This equation uses the mass fractions of total solids and water $\left(m_{s}\right.$ and $m_{w}$ respectively), the glass transition temperatures of lactose $\left(T_{\mathrm{gl}}\right)$ and water $\left(T_{\mathrm{gw}}\right)$, whose values were taken as $103^{\circ} \mathrm{C}$ and $-137^{\circ} \mathrm{C}$, and a constant, $k$, whose value was taken as 6.83 .

$T_{g}=\frac{T_{\mathrm{gl}}+k X_{w} T_{\mathrm{gw}}}{1+k X_{w}}, \quad$ where $X_{w}=\frac{m_{w}}{m_{s}}$ 
Once the glass transition temperature has been calculated the parameter $T-T_{g}$ is then calculated. This value is correlated to the stickiness of the powder where a higher $T-T_{g}$ results in a higher stickiness (adhesiveness).

\section{Methods}

\subsection{Test rig operation}

The experimental setup is schematically shown in Fig. 1. The test rig allows milk powder to be added to an air stream of controlled temperature and humidity. This powder laden airflow is then contacted in cross-flow with various geometries. The air temperature is controlled using three separate thermal operations. First a plate-fin liquid to air heat exchanger circulates heated water to preheat air. The air is drawn in by a fan and blown along the test duct. A small amount of direct steam injection further increases the temperature of the air while achieving the target humidity. Finally an electric heater connected to a VSD (Variable Speed Drive) is used as a trimming element to adjust the final temperature of the air stream.

An orifice plate in the duct provides a pressure drop which is related to the air velocity in the air duct and used to control the fan speed via a PID feedback loop to ensure a constant flow rate through the system as fouling on the tubes occurred. The orifice plate consists of a $10 \mathrm{~mm}$ lip on the top-side of the duct. This plate also creates a region of low pressure immediately behind the plate where milk powder is injected, aided by a little suction induced by the orifice plate. The powder laden airflow then travels through the test duct where fully developed turbulent flow is to be achieved before contact with the deposition surfaces. To control the rate of powder injection, a bottle full of powder is mechanically tapped. On average powder was added at $2.4-3.8 \mathrm{~g} / \mathrm{min}$ and test durations ranged from 20 to 80 min depending on the rate of deposition, i.e. $\mathrm{d} m_{f} / \mathrm{d} t$. At an air velocity of $4.5 \mathrm{~m} / \mathrm{s}$, the concentration of milk powder is approximately $2.0 \mathrm{~g} / \mathrm{m}^{3}$ and for air at $6.5 \mathrm{~m} / \mathrm{s}$ the concentration is about $2.9 \mathrm{~g} / \mathrm{m}^{3}$, which is significantly higher than in industry to have an accelerate the test.

By adjusting the direct steam injection valve, it was attempted in the tests to achieve an absolute humidity of $50-60 \mathrm{~g} \mathrm{H}_{2} \mathrm{O} / \mathrm{kg}$ dry air as this relates directly to the moisture content at industrial milk spray dryer exhausts. The process of setting up the initial temperature and humidity of the test system took anywhere up to $3 \mathrm{~h}$. Rigorous start-up and operation procedures for the equipment were established to prevent condensation on the test section. In the event that condensation was evident, the results were invalidated.

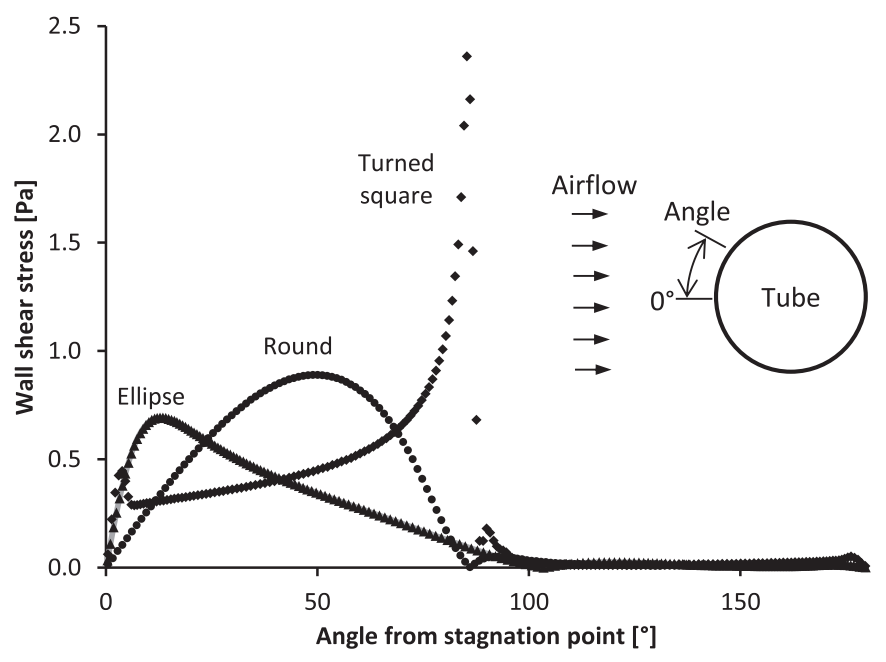

Fig. 2. Wall shear stress for round, elliptical and turned squared tubes using CFD.

Preventing condensation is a key reason why it often took several hours to achieve the desired conditions because temperature and humidity increased had to be done by small increments. Once the desired values were achieved and steadied, powder was added. The time for separate tests varied depending on the rate of deposition.

Throughout the course of the tests, deposition, pressure drop across the tube, and air temperature and humidity are visually observed and/or monitored. In general a test would be stopped when the pressure drop across the tube reached a constant level. Temperature and relative humidity were logged at $1 \mathrm{~s}$ intervals and $T-T_{g}$ was calculated for each interval and averaged for the entire test period. Two standard deviations of the temperature and relative humidity data for each test are used to estimate uncertainty in $T-T_{g}$. At the conclusion of each test the test assembly was removed from the duct and photographs were taken to show the deposition morphology from various angles.

\subsection{Bare tube test set-up}

Round $(25.4 \mathrm{~mm})$, elliptical $(22 \mathrm{~mm} \times 39 \mathrm{~mm})$, and turned square $(25.4 \mathrm{~mm} \times 25.4 \mathrm{~mm})$ tubes were housed horizontally in a cross-flow fashion in a section with transparent acrylic walls enabling visual inspection of the test. The hydraulic diameters tubes are: round is $25.4 \mathrm{~mm}$, elliptical is $22.9 \mathrm{~mm}$ and turned square is $25.4 \mathrm{~mm}$. Each tube was tested individually using various

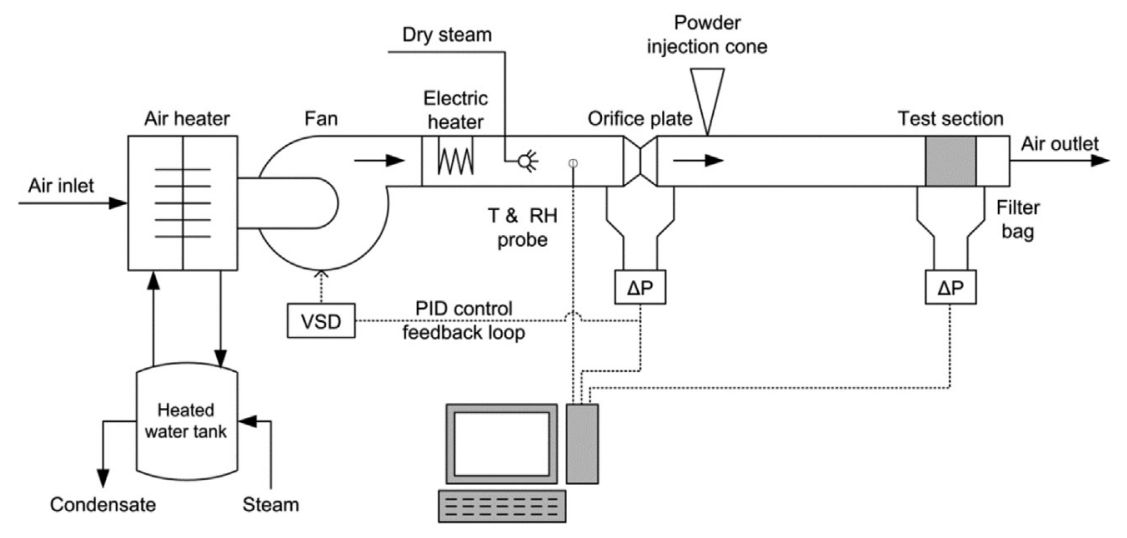

Fig. 1. Deposition test rig schematic. 
air temperatures $\left(46{ }^{\circ} \mathrm{C}-62{ }^{\circ} \mathrm{C}\right)$ to achieve a range of stickiness levels, $T-T_{g}$. Average duct velocities of 4.5 and $6.5 \mathrm{~m} / \mathrm{s}$ are used in the tests.

Photographs looking down the tubes were taken at regular intervals in an attempt to observe the growth of deposition over time. These images, depending on the clarity of the deposition layer, were later analysed to measure the location of deposition on each tube. Based on the photos, measurements and the tube geometry, the average location for the edge of the fouling layer was calculated using MatLab ${ }^{\mathrm{TM}}$. This result was then compared with flow simulation CFD results (Fig. 2) to determine the critical wall shear stress at the location where deposition ceased. CFD models included a single tube in an $80 \mathrm{~mm}$ square duct (same as the experimental) using the modelling parameters outlined by Walmsley et al. [8].

\subsection{Particle size distribution}

Non-agglomerated Skim Milk Powder is used in all tests. The particle size distribution was measured in iso-propanol using a Malvern Mastersizer 2000 according to the method of Pisecky [17]. By cumulative volume fraction, the mid diameter of the powder, $d(50 \%)$, was measured as $104 \mu \mathrm{m} ; d(10 \%)=39 \mu \mathrm{m}$ and $d(90 \%)=202 \mu \mathrm{m}$.

\subsection{Determination of $T-T_{g}{ }^{*}$}

Particle stickiness or $T-T_{g}{ }^{*}$ is defined in the same manner as Walmsley et al. [12] where $T$ is taken as the air temperature (dry bulb) and $T_{g}$ is calculated using the Gordon-Taylor equation (Eq. (2)). Wall temperature effects on $T-T_{g}$ are accounted for using the equation presented in Walmsley et al. [12]. $T-T_{g}{ }^{*}$ differs from the conventional definition of $T-T_{g}$ in that it is corrected for a minor wall temperature effect. This wall temperature effect was quantified by Walmsley et al. [12].

\section{Experimental results for single tubes in cross-flow}

\subsection{Fouling coverage and location}

The stickiness of the milk powder, as quantified by $T-T_{g}{ }^{*}$, was shown to influence the coverage and morphology of deposits around the front of the tubes. Fig. 3 shows photographs of three tests performed on the round tube at an air velocity of $4 \mathrm{~m} / \mathrm{s}$.
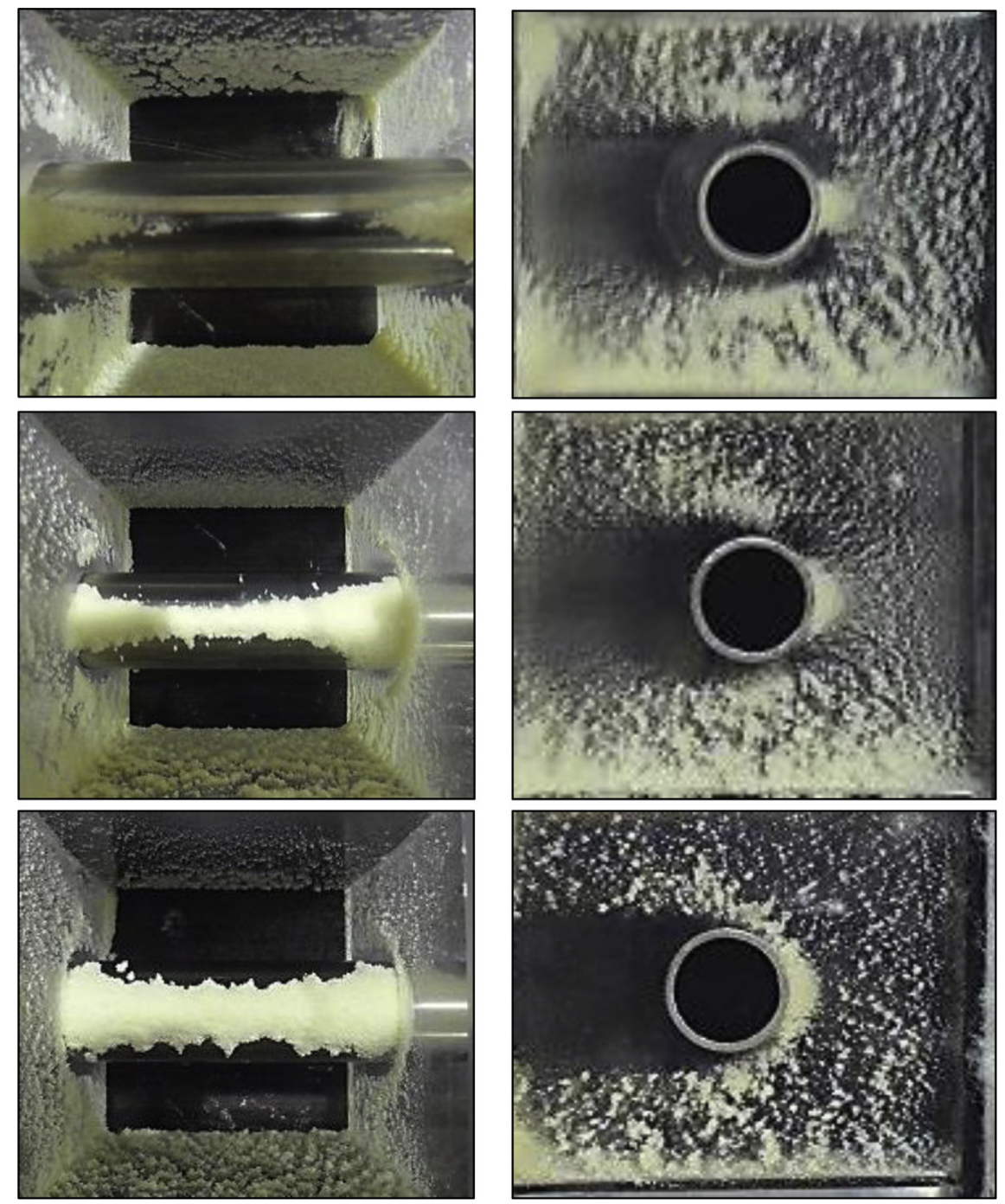

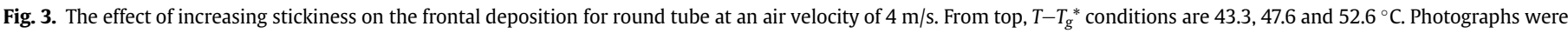
taken at the end of the test. 
Results are organised so that the top photographs are for the lowest $T-T_{g}{ }^{*}$ condition progressively down to the bottom photograph for the highest $T-T_{g}{ }^{*}$ condition. Increasing the stickiness of the powder is observed to significantly increase the fouling coverage around the front of the tube and the powder layer thickness.

The side angle photographs show the growth of the fouling layer near the wall. An airflow separation point on the front of the round tube is suggested by the deposits attached to the duct wall. Very little deposition was observed during any of the tests (for all three tube geometries) on the rear of the tubes. For each test condition, the wall of the ducting is seen to make an impact on the amount of deposition on the tube near the wall. Since the velocity profile is likely to be fully developed after travelling along a relatively long straight duct, air velocities near the duct wall are slower than in the centre of the duct, being zero at the wall boundary. As a result the particle impact velocity near the wall is progressively slower as particles impact closer to the wall, increasing the chance for particles to deposit.

The elliptical tube required higher $T-T_{g}{ }^{*}$ values to result in similar deposition amounts and coverage levels as the round tube for the same bulk air velocity as shown in Fig. 4. In terms of milk powder fouling properties the elliptical tube is, therefore, favourable over the round tube. The low fouling property of elliptical tubes has been demonstrated for tube bundles by researchers in other fields. For example Bouris et al. [18] applied both experimental and numerical approaches to conclude elliptical tube bundles were less susceptible to fouling.

Another benefit associated with the elliptical tube is the lower gas side flow resistance resulting in a lower pressure drop. Walmsley et al. [8] numerically evaluated the performance of round and elliptical tube bundles. In the models the same hydraulic airside diameter and frontal free-flow area for the two sets of tube bundles are constant so that the comparison between the tube geometries was fair. Their models suggested that the pressure drop across an elliptical tube bundle is about half of the pressure across a round tube bundle for the same air side heat transfer coefficient. Although in terms of compactness, the round tube bundle required about 30\% less volume (and heat transfer area) than the elliptical tube bundle to achieve the same heat transfer, but experienced a $150 \%$ greater pressure drop.

The turned square geometry is characterised by two flat $45^{\circ}$ angled sides facing the airflow. It was noticed in testing the turned square tube that no partial deposition occurred at intermediate
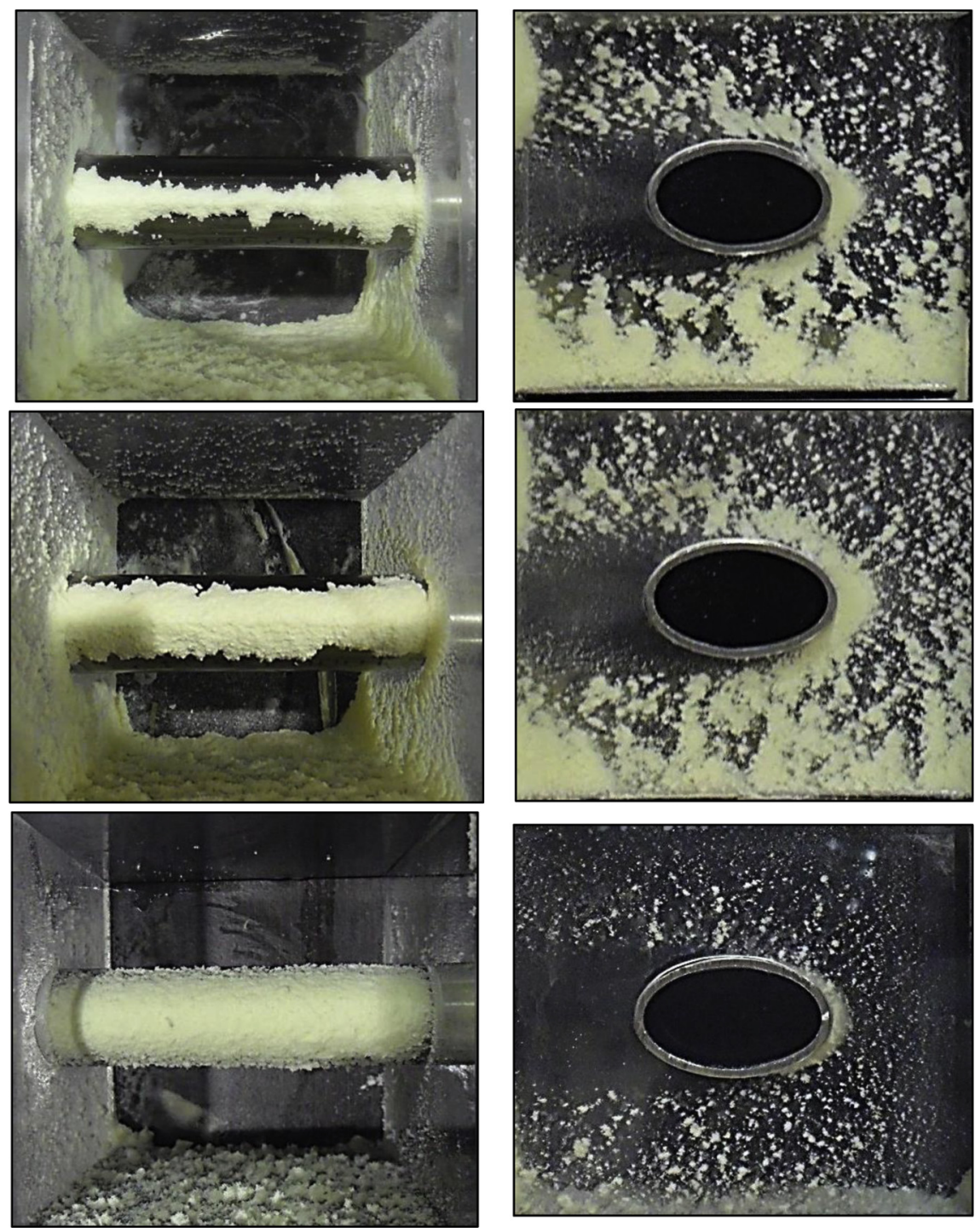

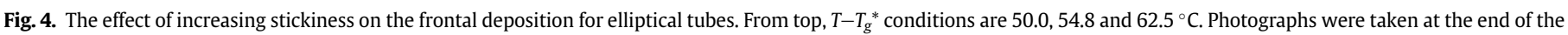
test. 

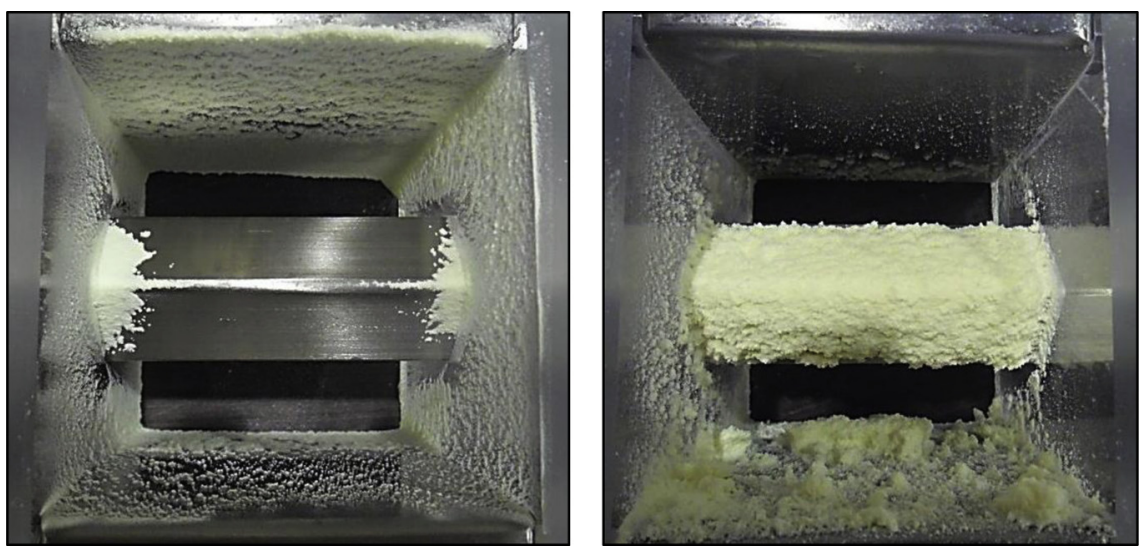

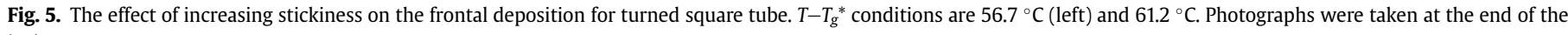
test.

$T-T_{g}$ values, as was seen for the round and elliptical tubes. Instead, there was either very little deposition (Fig. 5 left), or a fouling layer completely covering the front face of the tube (Fig. 5 right), as the stickiness was increased. These test results suggest there is a critical combination of impact angle (and/or wall shear stress) and particle stickiness that first initiates deposition to cover the surface of the turned square tube. Once again the small amount of deposition in Fig. 5 (left) near the wall is likely the result of wall slowing the air velocity.

Fig. 6 presents photographs of the deposition morphology for round tube and elliptical tube. The surface of the deposition on the front of the tubes typically had a small rounded peak that extended on an angle back to the tube at which point deposition ceased. The angled sides of the deposition were flat but rough. The deposition layer always peaked near the duct walls.

\subsection{Critical wall shear stress and critical impact angle}

The initial focus of the experimental analysis is to investigate how the local wall shear stress around the profile of various tubes influences particulate deposition. Three observations were expected in relation to this concept. First, it was expected that increasing $T-T_{g}{ }^{*}$ would require a higher wall shear stress to prevent deposition. Second, if wall shear stress is a determining factor for deposition, then it is expected that there is a clear correlation between wall shear stress and $T-T_{g}{ }^{*}$ that may be independent of the tube geometry and average bulk airflow velocity. Third, it was expected that deposition may favour the rear facing side of the tube as shown by Paz et al. [7] for particulate deposition on tube bundles fouled by a diesel exhaust, which has already been shown to not be the case for milk powder deposition on tubes.

Based on these hypothesises a unique critical wall shear stress should exist for each $T-T_{g}{ }^{*}$ value. To test this hypothesis, the local wall shear stress at the location on the tube where deposition ceased is plotted against $T-T_{g}{ }^{*}$ for round, elliptical and turned square tubes in Fig. 7. Results display no clear correlation for the tests performed at various face velocities. This lack of correlation suggests that the size and momentum of the milk powder particles is sufficient to break through the shear layer around the tubes with little impact. In addition, deposition at the rear of the tube was observed to be minimal. These results imply that the transport regime and mechanism of the bulk of the particles is not diffusion controlled as was the case for Paz et al. [7]. An underlying reason for the difference between this work and Paz et al. is the particle relaxation time. As mentioned earlier, the particle relaxation time milk powder in heat exchangers falls in the particle inertia moderated regime for the transport and deposition mechanism. As a result milk powder particles in heat exchangers respond slowly to changes in velocity flow field changes. In contrast the particle relaxation time in the work of Paz et al. [7] was between 0.1 and $1 \mathrm{~s}$ indicating particle transport is turbulent diffusion-eddy impaction controlled.

In the situation where particle motion and direction does not deviate from that of the bulk fluid direction along the duct, particles impact the tube surface at an angle approximately equal to that of the bulk flow direction. The critical impact angle for a given air
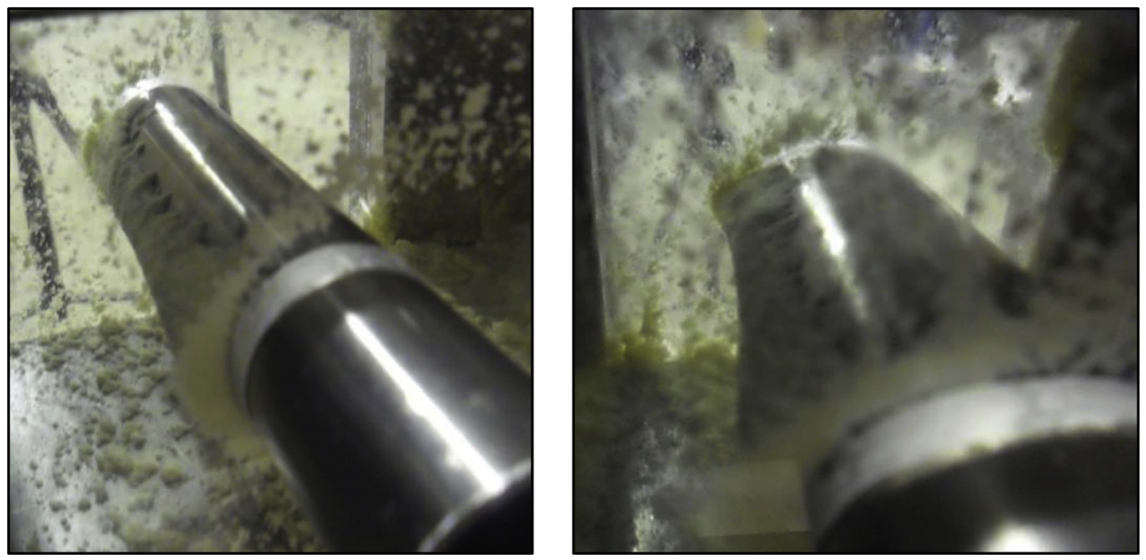

Fig. 6. Deposition morphology on round and elliptical tubes. $T-T_{g}{ }^{*}$ conditions are $52.6{ }^{\circ} \mathrm{C}$ (left) and $54.8^{\circ} \mathrm{C}$. Photographs were taken at the end of the test. 


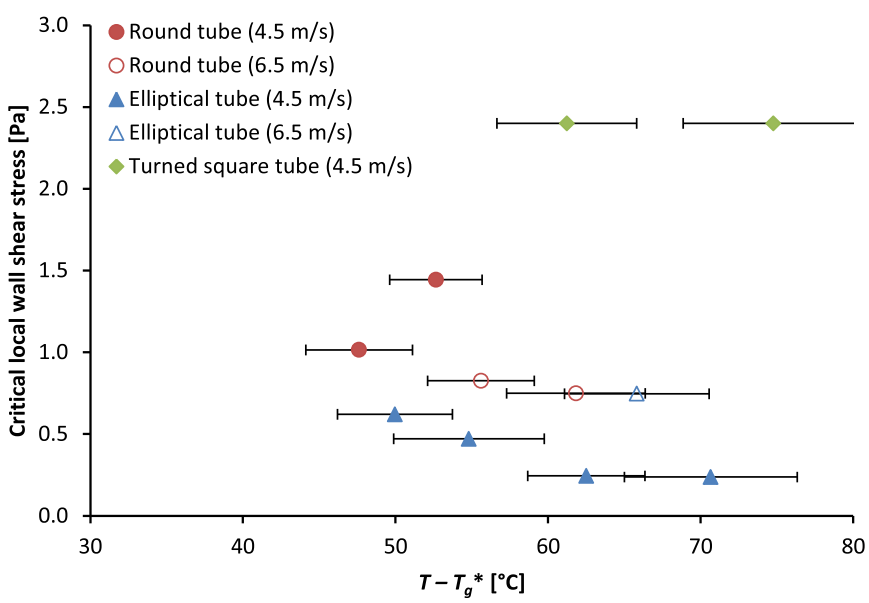

Fig. 7. Critical local wall shear stress plotted against $T-T_{g}$ for round, elliptical, and turned square tubes.

velocity and powder stickiness may be defined as the angle between the bulk flow direction and the normal to the tube surface at the point where deposition terminates, which is known from the experimental tests, for the round and elliptical tubes where the impact angle varies around the circumference of the tube. The general concept of a critical impact angle was originally suggested by Konstandopoulos [14]. Fig. 8 illustrates how the critical impact angle to the normal is estimated for deposition on the elliptical, round and square tubes. For the round tube this is merely the angle of the polar coordinate at the surface location. For the elliptical tube the angle varies from that of the polar coordinate as illustrated in Fig. 8a. For the turned square tube the angle remains constant at $45^{\circ}$ (considering only the positive angles) and as a result the tube was either clear or covered with deposition. The boundary between fouling and no fouling is defined by a critical combination of factors such as air velocity, stickiness, and impact angle. Therefore, in the case of the turned square tube, the critical combination of air velocity, stickiness, and impact angle is determined in the first instance by varying $T-T_{g}{ }^{*}$, instead of the impact angle, as can be done in the round and elliptical tube tests.

Fig. 9 plots the critical impact angle relative to the direction of the airflow against particle stickiness, $T-T_{g}{ }^{*}$. Vertical and horizontal bars in Fig. 9 represent the uncertainty of the measurements. Uncertainty in $T-T_{g}{ }^{*}$ was the result of fluctuating temperature and humidity measurements. Uncertainty in the critical impact angle is due the non-uniform deposition along the length of the tube. Predictions of the critical impact angle using the deposition model from Walmsley et al. [12] is included in Fig. 9 for comparison. When the uncertainty is taken into account, the deposition model from Walmsley et al. [12] appears to be sufficiently representative of the experimental data for single tubes in cross-flow. At $T-T_{g}{ }^{*}$ below $65^{\circ} \mathrm{C}$, the model provides a close match to the critical impact angle with the exception of the turned square tube; whereas at higher $T-T_{g}{ }^{*}$ the model over predicts the critical impact angle.

In the case of the turned square tube, it was found that either the entire face of the tube was clean or fouled. Increasing $T-T_{g}{ }^{*}$ after the tube fouled therefore gave an apparent "critical" impact angle of $45^{\circ}$ since there could be no impacts at angles greater than $45^{\circ}$. The minimum measured $T-T_{g}{ }^{*}$ required to cause the turned square tube to foul was $61.2{ }^{\circ} \mathrm{C}$ and the maximum measured $T-T_{g}{ }^{*}$ giving no fouling was $56.7^{\circ} \mathrm{C}$. The critical impact angle for the given air velocity and $T-T_{g}{ }^{*}$ lies, therefore, between $56.7{ }^{\circ} \mathrm{C}$ and $61.2^{\circ} \mathrm{C}$ for the turned square tube. The model predicts a $T-T_{g}{ }^{*}$ value of $53.6^{\circ} \mathrm{C}$. If the $T-T_{g}{ }^{*}$ uncertainty is taken into account, the measured $T-T_{g}{ }^{*}$ may be as low as $53.4{ }^{\circ} \mathrm{C}$, which marginally encompasses the model.

\subsection{Pressure drop}

The fouling growth rate and pressure drop across the tube are related. Fig. 10 plots the increase in pressure drop as a percentage for three stickiness levels for the round tube and one stickiness level for the elliptical tube. The data suggests the rate of pressure drop and, therefore, fouling build-up is dependent on the stickiness level, with higher stickiness conditions resulting in faster growth. Fouling was observed to reach an asymptote and this observation is reflected in the pressure drop measurements. When an asymptote

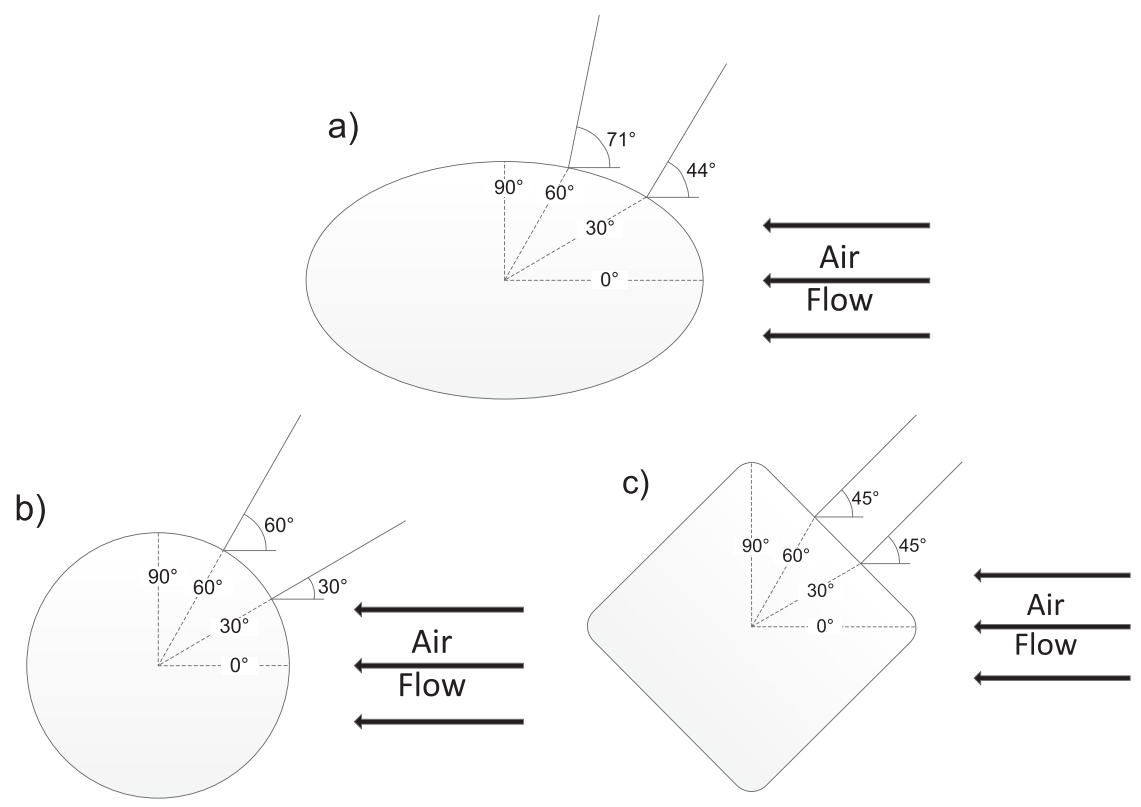

Fig. 8. Schematic showing how the impact angle is defined and how it changes for: a) elliptical tubes; b) round tubes; c) turned square tubes. 


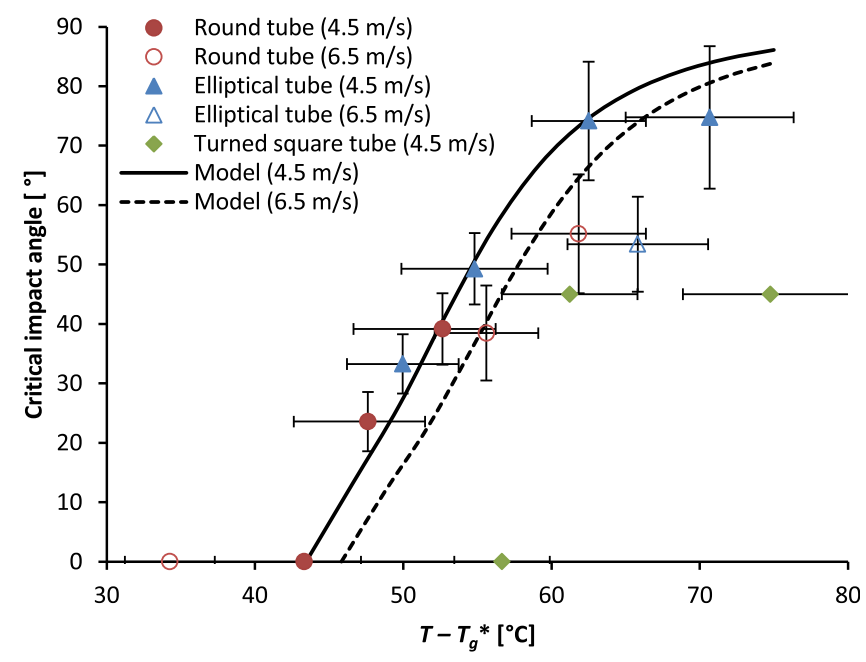

Fig. 9. Estimated critical impact angle for the round, elliptical and turned square tubes. The milk powder deposition model is taken from Walmsley et al. [12] and calculated using a particle diameter of $104 \mu \mathrm{m}$.

is reached, it implies the rate of fouling and removal are approximately the same.

A first order exponential approximation of the pressure drop increase with time is also plotted in Fig. 10 using the general equation.

$\Delta P(\%)=\Delta P_{\text {final }}(\%)\left(1-\exp \left(-\frac{t}{\alpha_{f}}\right)\right)$

where $t$ is the time from the start of the test and $\alpha_{f}$ is the time constant for the fouling, which is estimated as $420 \mathrm{~s}$. This time constant was similar for the round and elliptical tubes. Since the powder concentration is fairly low and it is unexpected to significantly influence the airflow profiles, it may be assumed that the supply of powder to heat exchanger surfaces is a key limiting factor for the rate of deposition. On the other hand the air velocity and stickiness of the powder determines the equilibrium amount of powder attached to a tube. As a result the final pressure drop increase is a function of stickiness for a given velocity profile and tube geometry whereas the time constant is a function of powder concentration, which may be estimated from the average powder injection rate. For different concentrations of powder the equivalent time constant for the pressure drop rise is estimated using

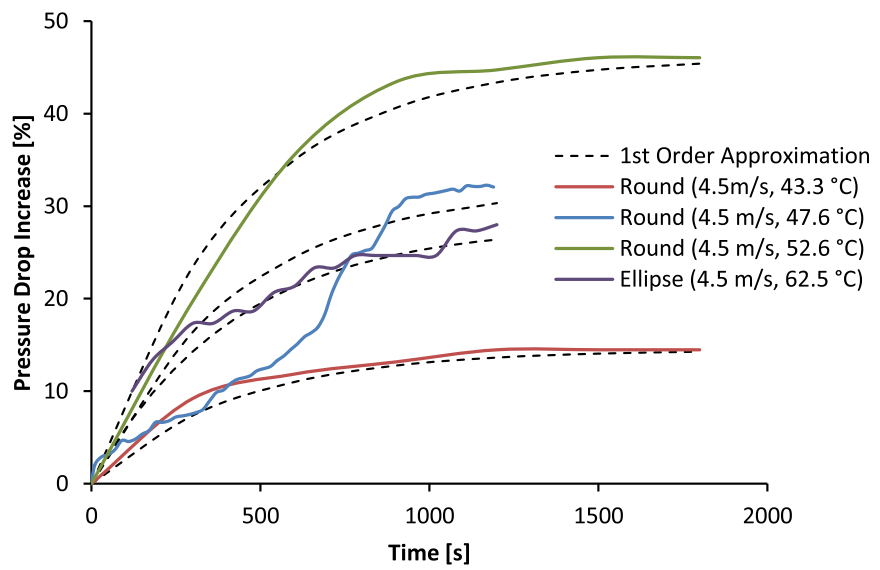

Fig. 10. Pressure drop over time across a single round tube for three levels of stickiness showing a first order exponential approximation with a time constant of $420 \mathrm{~s}$.

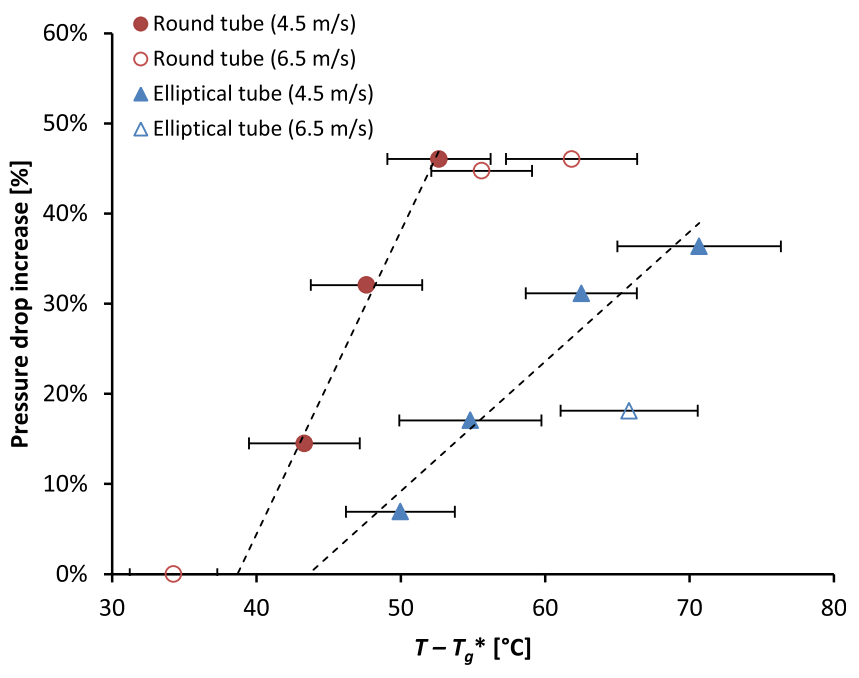

Fig. 11. Final pressure drop versus $T-T_{g}{ }^{*}$ for the round and elliptical tubes.

$\alpha_{f, 2}=\alpha_{f, 1} \frac{c_{b, 1}}{c_{b, 2}}$

where $c_{b}$ is the milk powder concentration in the bulk airflow. The final pressure drop increase percentages are plotted against $T-T_{g}{ }^{*}$ in Fig. 11. The round and elliptical tubes both experience increases in pressure drop with increasing $T-T_{g}{ }^{*}$. As $T-T_{g}{ }^{*}$ increases, the deposition coverage around the tubes grows adding resistance to the airflow. For the same $T-T_{g}{ }^{*}$ the pressure drop increase for the round tube is greater than for the elliptical tube. This conclusion reinforces the idea that the coverage of the frontal deposition for the round tube is greater than for the elliptical tube at the same $T-T_{g}{ }^{*}$.

\section{Conclusion}

Deposition results for tubes indicate milk powder deposition is influenced by the impact angle of the milk powder on the tube wall, which angle varies around the circumference for the round and elliptical tubes. Deposition mostly occurs on the front face of the round, elliptical and turned square tubes and decreases around each tube until a critical impact angle to the surface of the tube and deposition ceases. None of the tube geometries contained significant deposition on the rear side of the tube. The critical impact angle may be described by a literature deposition model for SMP and is independent of tube shape. Elliptical tube is shown to be naturally low fouling due to the shape of the tube.

\section{References}

[1] T.R. Bott, Fouling of Heat Exchangers, Elsevier, Amsterdam, The Netherlands, 1995.

[2] H. Müller-Steinhagen, H. Malayeri, A.P. Watkinson, Heat exchanger fouling: mitigation and cleaning techniques, Heat Transfer Eng. 32 (2011) 189-196.

[3] M.S. Abd-Elhady, C.C.M. Rindt, J.G. Wijers, A.A. Van Steenhoven, E.A. Bramer, T.H. van der Meer, Minimum gas speed in heat exchangers to avoid particulate fouling, Int. J. Heat Mass Transfer 47 (2004) 3943-3955, http://dx.doi.org/ 10.1016/j.ijheatmasstransfer.2004.03.024.

[4] Z. Jegla, B. KilkovskÝ, P. Stehlík, Calculation tool for particulate fouling prevention of tubular heat transfer equipment, Heat Transfer Eng. 31 (2010) 757-765, http://dx.doi.org/10.1080/01457630903500932.

[5] P. Stehlík, Conventional versus specific types of heat exchangers in the case of polluted flue gas as the process fluid - a review, Appl. Therm. Eng. 31 (2011) 1-13, http://dx.doi.org/10.1016/j.applthermaleng.2010.06.013.

[6] G. Zhang, T.R. Bott, C.R. Bemrose, Reducing particle deposition in air-cooled heat exchangers, Heat Transfer Eng. 13 (1992) 81-87. 
[7] C. Paz, E. Suárez, A. Eirís, J. Porteiro, Experimental evaluation of the critica local wall shear stress around cylindrical probes fouled by diesel exhaust gases, Exp. Therm. Fluid Sci. 38 (2012) 85-93, http://dx.doi.org/10.1016/ j.expthermflusci.2011.11.011.

[8] T.G. Walmsley, M.R.W. Walmsley, M.J. Atkins, J. Hoffman-Vocke, J.R. Neale Numerical performance comparison of different tube cross-sections for heat recovery from particle-laden exhaust gas streams, Procedia Eng. 42 (2012) 1476-1490, http://dx.doi.org/10.1016/j.proeng.2012.07.527.

[9] T.G. Walmsley, M.R.W. Walmsley, M.J. Atkins, J.R. Neale, Improving energy recovery in milk powder production through soft data optimisation, Appl. Therm. Eng. $61 \quad$ (2013) 80-87, http://dx.doi.org/10.1016/ j.applthermaleng.2013.01.051.

[10] T.G. Walmsley, M.R.W. Walmsley, M.J. Atkins, J.R. Neale, Fouling and pressure drop analysis of milk powder deposition on the front of parallel fins, Adv. Powder Technol. 24 (2013) 780-785, http://dx.doi.org/10.1016/ j.apt.2013.04.004.

[11] R.A. Murti, A.H.J. Paterson, D. Pearce, J.E. Bronlund, The influence of particle velocity on the stickiness of milk powder, Int. Dairy J. 20 (2010) 121-127, http://dx.doi.org/10.1016/j.idairyj.2009.08.005.
[12] T.G. Walmsley, M.R.W. Walmsley, M.J. Atkins, J.R. Neale, C.M. Sellers, An experimentally validated criterion for skim milk powder deposition on stainless steel surfaces, J. Food Eng. 127 (2014) 111-119, http://dx.doi.org/ 10.1016/j.jfoodeng.2013.11.025.

[13] A. Guha, Transport and deposition of particles in turbulent and laminar flow, Annu. Rev. Fluid Mech. 40 (2008) 311-341.

[14] A.G. Konstandopoulos, Particle sticking/rebound criteria at oblique impact, J. Aerosol. Sci. 37 (2006)292-305, http://dx.doi.org/10.1016/j.jaerosci.2005.05.019.

[15] S. Palzer, The effect of glass transition on the desired and undesired agglomeration of amorphous food powders, Chem. Eng. Sci. 60 (2005) 3959-3968, http://dx.doi.org/10.1016/j.ces.2005.02.015.

[16] G.F. Brooks, The Sticking and Crystallisation of Amorphous Lactose, M. Tech, Massey University, 2000.

[17] I. Pisecky, Handbook of Milk Powder Manufacture, Niro A/S, Copenhagen, Denmark, 1997.

[18] D. Bouris, E. Konstantinidis, S. Balabani, D. Castiglia, G. Bergeles, Design of a novel, intensified heat exchanger for reduced fouling rates, Int. J. Heat Mass Transfer 48 (2005) 3817-3832, http://dx.doi.org/10.1016/j.ijheatmasstransfer.2005.03.026. 